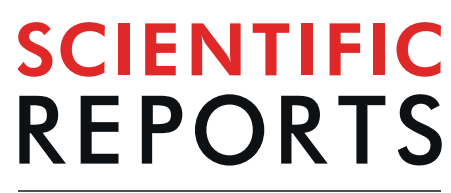

natureresearch

Check for updates

\title{
Pregnancy rates after slow-release insemination (SRI) and standard bolus intrauterine insemination (IUI) - A multicentre randomised, controlled trial
}

\author{
Julian Marschalek ${ }^{1}$, Christian Egarter ${ }^{1}$, Elisabeth Vytiska-Binsdorfer ${ }^{1}$, Andreas Obruca ${ }^{2}$, \\ Jackie Campbell ${ }^{3}$, Philip Harris ${ }^{4}$, Maarten van Santen ${ }^{5}$, Bernd Lesoine ${ }^{6}$, Johannes Ott ${ }^{1}$ \& \\ Maximilian Franz ${ }^{1 凶}$
}

This multicentre, randomised, controlled cross-over trial was designed to investigate the effect of intrauterine slow-release insemination (SRI) on pregnancy rates in women with confirmed infertility or the need for semen donation who were eligible for standard bolus intra-uterine insemination (IUI). Data for a total of 182 women were analysed after randomisation to receive IUI $(n=96)$ or SRI $(n=86)$ first. The primary outcome was serological pregnancy defined by a positive beta human chorionic gonadotropin test, two weeks after insemination. Patients who did not conceive after the first cycle switched to the alternative technique for the second cycle: 44 women switched to IUI and 58 switched to SRI. In total, there were 284 treatment cycles (IUI: $n=140 ;$ SRI: $n=144$ ). Pregnancy rates following SRI and IUI were $13.2 \%$ and $10.0 \%$, respectively, which was not statistically significant $(p=0.202)$. A statistically significant difference in pregnancy rates for SRI versus IUI was detected in women aged under 35 years. In this subgroup, the pregnancy rate with SRI was $17 \%$ compared to $7 \%$ with IUI (relative risk 2.33 ; $p=0.032$ ) across both cycles. These results support the hypothesis that the pregnancy rate might be improved with SRI compared to standard bolus IUI, especially in women aged under 35 years.

Globally, 10-15\% of couples of reproductive age are affected by infertility ${ }^{1}$. Following diagnosis of infertility, and evaluation of its causes, couples can be provided with information about their likelihood of achieving a spontaneous pregnancy, and their chance of pregnancy after different treatment options. Intrauterine insemination (IUI) is often the first step in infertility treatment for couples with unexplained infertility, low-grade endometriosis, sexual function disorders and low-grade male subfertility ${ }^{2}$. Pregnancy rates following artificial insemination are low ${ }^{3}$ and depend on several factors, including: age; reason for sub-fertility or infertility; absence/presence and type of ovarian stimulation and timing of insemination ${ }^{3,4}$ as well as the number of inseminated motile sperm ${ }^{5,6}$.

A large retrospective cohort study, covering more than 15,000 IUI-cycles, reported a mean pregnancy rate of $5.6 \%$ per cycle, and cumulative ongoing pregnancy rates after the third, seventh and ninth cycles of $18 \%$, $30 \%$ and $41 \%$, respectively ${ }^{7,8}$. These data clearly show the importance of developing new strategies for improving pregnancy rates after IUI. Most studies that have investigated methods for improving pregnancy rates after IUI have focused on the choice of clomiphene citrate (CC; now being superseded by letrozole) or recombinant follicle stimulating hormone $(\mathrm{rFSH})$, with or without the use of gonadotropin-releasing hormone $(\mathrm{GnRH})$ antagonists to stimulate ovulation ${ }^{9-13}$. Some studies dealt with the question of immobilisation versus immediate mobilisation following the insemination procedure - as immediate mobilisation might cause leakage of spermatozoa out of the

${ }^{1}$ Department of Obstetrics and Gynecology, Medical University of Vienna, Waehringer Guertel 18-20, 1090, Vienna, Austria. ${ }^{2}$ Kinderwunschzentrum Goldenes Kreuz, Lazarettgasse 16, 1090, Vienna, Austria. ${ }^{3}$ Faculty of Health and Society, University of Northampton, Northampton, NN2 7AL, UK. ${ }^{4}$ Department of Gynaecology, Wrightington Hospital, Wigan, Lancashire, WN6 9EP, UK. ${ }^{5}$ Private Office and Spermbank, Kriegsstrasse 216, 76135, Karlsruhe, Germany. ${ }^{6}$ A.R.T. Bogenhausen, Prinzregentenstraße 69, 81675, Munich, Germany. ${ }^{凶}$ e-mail: mf@gynbogenhausen.de 
uterus - and provided conflicting results ${ }^{14-16}$. However, only a few studies have dealt with changes to the IUI technique itself, or have questioned the application $\operatorname{method}^{5}$. One alternative to IUI is intratubal insemination (ITI), also known as fallopian tube sperm perfusion (FSP). This technique differs from IUI in that a higher volume of prepared semen is used ( $4 \mathrm{ml}$ compared with $\leq 0.5 \mathrm{ml}$ ) and is introduced directly into the fallopian tubes ${ }^{17}$. The hypothesis is that the presence of a higher sperm density in the fallopian tubes at the time of ovulation is more likely to result in pregnancy; however, available evidence suggests that there is no clear benefit for ITI/FSP over $\mathrm{IUI}^{18-20}$. Another modified IUI application technique is slow release insemination (SRI), which was first described in $1992^{21}$. The authors hypothesised that a persistent low concentration of spermatozoa might prolong the period of potential fertilisation and thereby mimic physiological sperm transportation from the cervix to the fallopian tube. We have recently published data from two pilot randomised, controlled cross-over studies that indicate a statistically significant advantage of SRI over conventional bolus IUI ${ }^{22}$. The present, larger, multicentre trial was performed to clarify the effect of intra-uterine SRI on pregnancy rates in women designated for standard bolus IUI.

\section{Materials and Methods}

Study design and patient population. This multicentre, randomised, controlled cross-over trial was conducted in women with infertility and/or the need for semen donation who were eligible for IUI in 11 fertility centres across Europe. As already stated in a prior pilot study ${ }^{22}$, the cross-over design was chosen because it has been shown to give results comparable to those from studies with a parallel design, and, thus, to be a valid approach for infertility trials ${ }^{23,24}$.

Oral and written informed consent was obtained from all participants. The study was approved by the main ethics committee of the Medical University of Vienna (EK 1227/2012) and by all other local ethics committees. It was conducted in accordance with the Declaration of Helsinki and was registered in the Current Controlled Trials Register (registration number NCT02315040, 19/10/2014).

Patients were recruited between October 2012 and June 2017. Women were included if they fulfilled all of the following criteria: ${ }^{22}$ (i) primary or secondary infertility, defined as a couple's failure to conceive after 12 months of attempting conception; (ii) age 20-40 years; (iii) tubal patency as diagnosed by hysterosalpingography, hystero-contrast-sonography (hycosy) or dye test with a maximum time interval between tubal testing and the woman's enrolment into the study of 12 months; (iv) since the total motile sperm count is a major factor which influences pregnancy changes after IUI ${ }^{25}$, a minimum of 10 million motile sperm cells/ millilitre (mio/ml) after preparation; ( $v$ ) infertility due to anovulation and/or endometriosis and/or the need for semen donation and/or unexplained infertility. In this context, unexplained infertility is defined as the absence of a definable reason for a couple's failure to conceive after 12 months of attempting conception despite a detailed evaluation of ovulation, tubal and uterine abnormalities and male infertility factors.

Patients with uterine abnormalities, such as a septate uterus, were excluded.

A computerised randomisation programme was used initially to assign women to either the standard bolus IUI treatment or the SRI method. Women who failed to conceive in this first course of treatment were then allocated to the alternative method for the second treatment.

The primary outcome parameter was serological pregnancy defined as a positive beta human chorionic gonadotropin (hCG) test (in urinary or blood samples) two weeks after insemination. Information on the patient's age, gravidity, cause of infertility, reproductive and concomitant medications was collected along with information on her partner's age, sperm motility, sperm count and percentage of normal/abnormal sperm according to the analysis on the day of the SRI or IUI procedure. Details of any adverse events (AEs) were also recorded.

Follicle monitoring and ovarian stimulation. In unstimulated cycles transvaginal sonography for follicular monitoring was performed depending on the anticipated ovulation between day 10 and 14 of the menstrual cycle and was continued until a follicle size over $18 \mathrm{~mm}$ was reached. 35-38 hours after endogenous LH-surge or ovulation induction with human chorionic gonadotropin (hCG) 5,000 or 10,000IU intramuscularly (Pregnyl ${ }^{\circledR}$, Merck Serono; Brevactid ${ }^{\circledR}$, Ferring Pharmaceuticals; Choragon ${ }^{\circledR}$, Ferring Pharmaceuticals) or chorionic gonadotropin alpha 250 or $500 \mu \mathrm{g}$ subcutaneously (Ovitrelle ${ }^{\circledR}$, Merck Serono) the insemination (IUI/SRI) was performed.

Controlled ovarian stimulation was performed either with human menopausal gonadotropin (Menopur ${ }^{\circledR}$, Ferring Pharmaceuticals) or Follitropin alpha/beta (Gonal F ${ }^{\circledR}$, Merck Serono; Puregon ${ }^{\circledR}$, Merck Sharp \& Drohne) or combined Follitropin alpha/Lutropin alpha (Pergoveris ${ }^{\circledR}$, Merck Serono) 75 IU subcutaneously starting from day 3-5 of the menstrual cycle or with clomiphene citrate $50 \mathrm{mg}$ from day 5-9. Follicular monitoring was started on day 10 until a follicle size over $18 \mathrm{~mm}$ was recorded. 35-38 hours after ovulation induction with hCG 5,000 or $10,000 \mathrm{IU}$ intramuscularly (Pregnyl ${ }^{\circledR}$, Merck Serono; Brevactid ${ }^{\circledR}$, Ferring Pharmaceuticals; Choragon ${ }^{\circledR}$, Ferring Pharmaceuticals) or chorionic gonadotropin alpha 250 or $500 \mu \mathrm{g}$ subcutaneously (Ovitrelle ${ }^{\circledR}$, Merck Serono) the insemination (IUI/SRI) was performed. Cycles were cancelled if more than 2 follicles over $16 \mathrm{~mm}$ were present. In stimulated cycles women received either vaginal progesterone $200 \mathrm{mg}$ once daily or dydrogesterone $10 \mathrm{mg}$ twice daily for 14 days.

Sperm preparation method. The sperm preparation method was performed according to the World Health Organisation laboratory manual for the examination and processing of human semen (2010) either with density gradient preparation $(n=144 / 284)$ or swim up procedure $(n=140 / 284)$ from good quality samples using commercially available media (GM501 SpermAir - Gynemed GmbH \& Co. KG, Lensahn, Germany; Gynemed Gradient 45\%/90\% - Gynemed GmbH \& Co. KG, Lensahn, Germany; Origio sperm preparation medium Origio, Måløv, Denmark). 


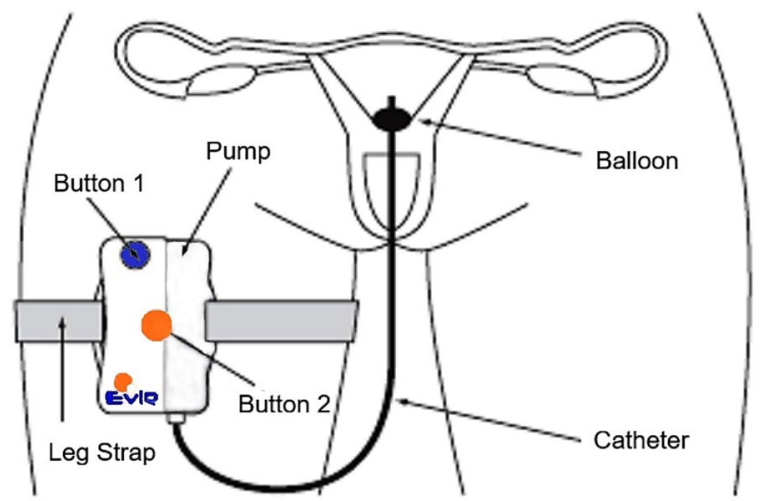

Figure 1. Schematic Illustration of the EVIE Slow Release Insemination Pump. (Figure by courtesy of Fertiligent Ltd.).

Density gradient preparation: Application of each 1-1.5 $\mathrm{ml}$ of $45 \%$ and $90 \%$ gradient on the bottom of a conical test tube. Centrifugation of the test tube between $500-1,500 \mathrm{rpm}$, depending on sperm-counts, for 20-30 minutes (24-210xg). Aspiration of the pellet and resuspension with 2-5 $\mathrm{ml}$ of buffer. Centrifugation at $1,500-2,000 \mathrm{rpm}$ for 10 minutes $(210-380 \mathrm{xg})$. Evaluation of sperm concentration and progressive motility.

Swim up procedure: Transfer of $1.5 \mathrm{ml}$ of buffer into a test tube at a temperature of $25-36^{\circ} \mathrm{C}$. Injection of $0.5 \mathrm{ml}$ of the sperm sample with a sterile $1 \mathrm{ml}$ syringe in the bottom of the test tube. Incubation of the test tube for 15 to 30 minutes at a temperature of $35-36^{\circ} \mathrm{C}$.

Lift of the supernatant with motile sperm cells and transfer to a sterile test tube. Evaluation of sperm concentration and progressive motility.

Standard bolus IUI technique. The standard bolus IUI is accomplished as described elsewhere ${ }^{22}$ with a polyethylene insemination catheter ( 5 French, $28 \mathrm{~cm}$ ). Before performing the IUI, the catheter is joined to a $1 \mathrm{ml}$ tuberculin syringe containing laboratory-prepared sperm. This is connected to the insemination catheter, which is inserted into the uterine cavity. After the injection of sperm and removal of the catheter, the patient is able to leave the clinic.

SRI technique. In this study, the EVIE device was used for women undergoing SRI. The device consists of a disposable EVIE syringe pump (Fertiligent, Ra'anana, Israel), a $3 \mathrm{ml}$ sterile syringe (Becton Dickinson; Franklin Lakes, NJ) and a customised HSG catheter with inflatable anchor balloon at the tip (Catheter Research Inc; Indianapolis, IN). The disposable pump (Fig. 1) is a mechanical device in which a spring pushes the syringe plunger with a patented spring restriction mechanism; this allows it to keep running during the four-hour delivery period. Prepared sperm solution is held in a sterile, sperm-compatible syringe in the chamber of the EVIE device before being delivered through the catheter over four hours. The insertion of the catheter into the uterus is performed as for standard IUI. In contrast to the standard IUI procedure, however, after positioning the EVIE catheter into the uterine cavity, it is anchored in the uterus by using normal saline solution ( $1 \mathrm{ml})$ to fill the balloon positioned at the end of the catheter. The pump is strapped to the patient's thigh and the device is activated by pressing button marked number 1 . The patient is able to remain mobile (completely ambulatory) during the four-hour insemination procedure. There is no need for her to rest, and she may leave the clinic to go home. Once four hours has elapsed, button number 2 is pressed. This completes the procedure by flushing any remaining sperm in the syringe into the uterus. The patient removes the catheter herself by opening the white stopcock to empty the balloon before withdrawing the catheter. The entire device is then discarded.

Sample size calculation. The a priori sample size for the study was calculated using a minimum clinically significant effect defined as a relative risk of 2.0 in favour of SRI and an estimated pregnancy rate for IUI for women aged $<40$ years of $14.3 \%$ (which was observed in an unpublished pilot data set). Using these estimates, a minimum sample size of 137 treatment cycles per group (treating each insemination as a separate case) was required for a superiority trial with a power of $90 \%$ and a significance level of 0.05 .

Statistical analysis. Data for a maximum of two cycles (one SRI and one IUI per woman) only were analysed. Data from patients who withdrew due to adverse effects or device failure, or who failed to comply with the protocol, were treated as missing. Because of the nature of the study design, each treatment (rather than each person) was considered as an independent case.

For numerical parameters, variables are summarised as either mean \pm standard deviation (SD) or median with inter-quartile range (IQR) depending on the data distribution. For categorical parameters, data are presented as frequencies and percentages.

Chi-squared or Fishers' exact tests were used to compare categorical variables between the two groups and independent-samples median tests were used to compare non-parametric numerical variables. One-tailed z-tests were used to test for superiority (i.e. relative risk [RR] of $>1$ ) of the pregnancy rate of SRI over IUI. 


\begin{tabular}{|c|c|c|c|}
\hline & $\begin{array}{l}\text { IUI procedures } \\
(\mathrm{n}=140)\end{array}$ & $\begin{array}{l}\text { SRI procedures } \\
(\mathrm{n}=144)\end{array}$ & p-value ${ }^{b}$ \\
\hline Female age, years* & $33(30-36)$ & $33(30-36)$ & 0.840 \\
\hline Body Mass Index $\left(\mathrm{kg} / \mathrm{m}^{2}\right)^{*}$ & $22(20-24)$ & $22(20-24)$ & 0.899 \\
\hline \multicolumn{4}{|l|}{ Previous pregnancies } \\
\hline $0^{*}$ & $81(58 \%)$ & $91(63 \%)$ & 0.511 \\
\hline $1^{\#}$ & $47(33 \%)$ & $39(27 \%)$ & \\
\hline$>1^{\#}$ & $12(9 \%)$ & $13(9 \%)$ & \\
\hline \multicolumn{4}{|l|}{ Cause of infertility } \\
\hline Endometriosis $^{\#}$ & $10(7 \%)$ & $11(7 \%)$ & 0.672 \\
\hline Anovulation ${ }^{*}$ & $22(16 \%)$ & $27(19 \%)$ & \\
\hline Unexplained infertility $^{*}$ & $108(77 \%)$ & $105(73 \%)$ & \\
\hline Donor Insemination ${ }^{\#}$ & $19(14 \%)$ & $18(13 \%)$ & 0.789 \\
\hline \multicolumn{4}{|l|}{ Reproductive Medication ${ }^{*}$} \\
\hline Clomiphene & 48 & 49 & 0.963 \\
\hline Gonadotropins & 89 & 90 & 0.852 \\
\hline Progesterone & 33 & 33 & 0.896 \\
\hline \multicolumn{4}{|l|}{ Concomitant Medication } \\
\hline Levothyroxine & 9 & 8 & 0.757 \\
\hline Other $^{\mathrm{c}}$ & 4 & 6 & 0.549 \\
\hline Male age, years* & $36(33-40)$ & $35.5(32-39)$ & 0.468 \\
\hline \multicolumn{4}{|l|}{ Semen analysis ${ }^{\mathrm{a}}$} \\
\hline Concentration $(\mathrm{mio} / \mathrm{ml})^{*}$ & $45(17-77)$ & $40(15-77)$ & 0.468 \\
\hline Motility $(\%)^{*}$ & $55(45-75)$ & $54(45-73)$ & 0.519 \\
\hline Normal morphology $(\%)^{*}$ & $19(6-75)$ & $12(5-80)$ & 0.394 \\
\hline \multicolumn{4}{|l|}{ Treatment cycle } \\
\hline $1^{\#}$ & 96 & 86 & 0.120 \\
\hline $2^{\#}$ & 44 & \begin{tabular}{|l|l}
58 \\
\end{tabular} & \\
\hline
\end{tabular}

Table 1. Baseline characteristics of all couples undergoing IUI and SRI procedures. IUI, intrauterine insemination; SRI, slow-release insemination. Data are presented as *median (interquartile range) or ${ }^{*} \mathrm{n}(\%)$. ${ }^{*}$ Reproductive

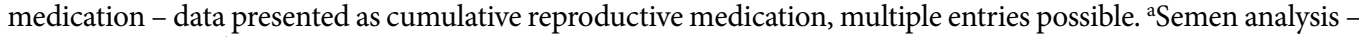

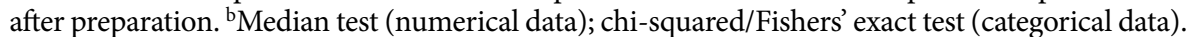

IBM SPSS 22.0 (SPSS Inc; Chicago, IL) was used for statistical analysis. P-values of less than 0.05 were considered statistically significant.

Ethical approval. The study was approved by the main ethics committee of the Medical University of Vienna (EK 1227/2012) and by all other local ethics committees. All procedures performed in studies involving human participants were in accordance with the ethical standards of the institutional and/or national research committee and with the 1964 Helsinki declaration and its later amendments or comparable ethical standards. The study was registered in the Current Controlled Trials Register (registration number NCT02315040).

Informed consent. Oral and written informed consent was obtained from all participants.

\section{Results}

A total of 183 women were randomised into the two treatment arms (Fig. 1): 96 (52.5\%) women received standard IUI treatment first and 87 (47.5\%) women received SRI treatment first. The EVIE device did not fully actuate in one patient assigned to the SRI group: she received a bolus at the end of the 4-hour administration period and her data were excluded from the analysis. Characteristics for analysed patients and their partners are shown in Table 1: there were no significant differences between the two groups. The median age of women participating in the study was 33 years (IQR 30-36 years). Donor sperm was used in 37 treatments for 23 women (13\%). 102 women underwent a second treatment cycle (IUI: $n=44$; SRI: $n=58$; Fig. 2). In total, there were 284 treatment cycles (IUI: $n=140$; SRI: $n=144$ ).

The observed overall serological pregnancy rate for SRI was $13.2 \%$, compared to $10.0 \%$ for IUI (relative risk $[R R]=1.32$ ); however, this difference was not statistically significant (95\% confidence interval [CI] 0.69-2.53; $\mathrm{p}=0.202)$.

Effect of age on pregnancy rates. In total, 172 inseminations were performed in patients aged under 35 years (IUI: $\mathrm{n}=83$; SRI: $\mathrm{n}=89$ ). For all women aged under 35 years undergoing SRI, the observed RR for pregnancy was 2.33 , with $16.9 \%$ of the SRI procedures resulting in pregnancy $(n=15)$ compared to $7.2 \%$ of the IUI procedures $(n=6)$. This difference was statistically significant $(\mathrm{p}=0.032)$. There were no significant differences 


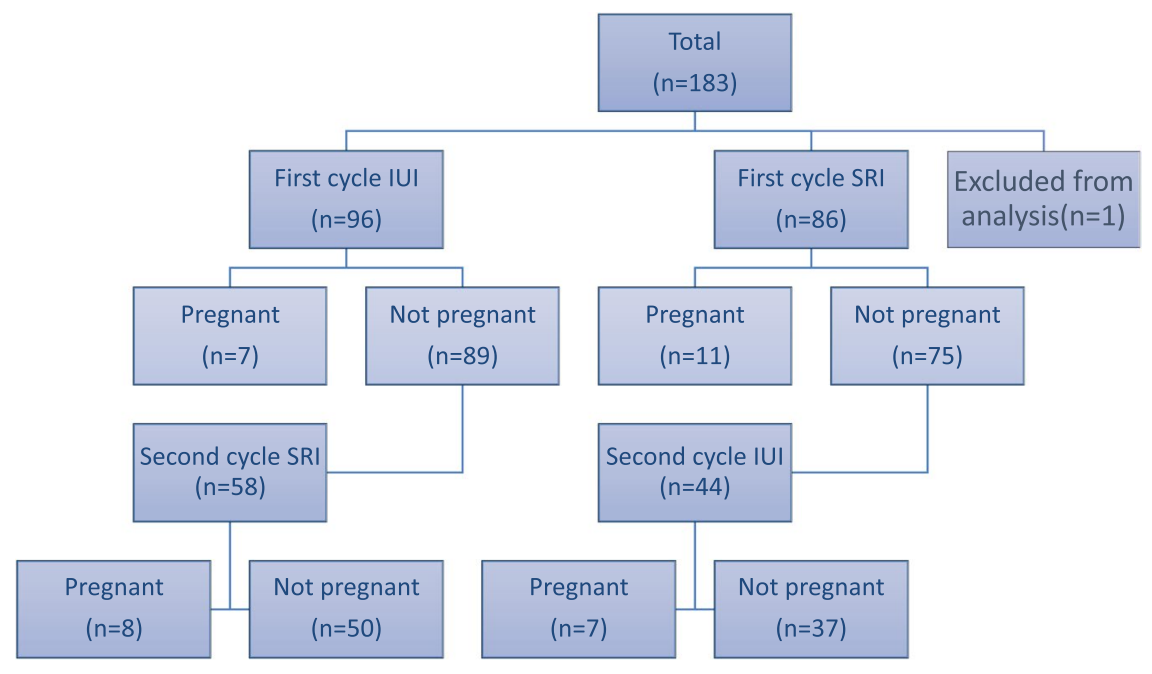

Figure 2. Flow chart showing the initial randomisation to IUI or SRI, pregnancy rates and numbers of patients crossing over to the alternate procedure. (IUI, intrauterine insemination; SRI, slow-release insemination).

with respect to female and male characteristics for patients aged under 35 years in the IUI and SRI subgroups (Table 2). Total pregnancy rates following SRI and IUI are provided in Table 3.

Safety. There were no significant differences in the proportions of women reporting adverse events with the SRI procedure compared to the IUI procedure $(7 / 144$ vs. $1 / 140, \mathrm{p}=0.071)$ (Table 4$)$. Two patients who experienced pain during catheter insertion, and one patient with syncope did not proceed with SRI treatment, but all other patients who reported adverse events did. No serious adverse events were recorded. With respect to pregnancy related complications there were 3 ectopic pregnancies reported following SRI and none following IUI. However, this difference was not statistically significant $(p=0.248)$ (Table 4).

\section{Discussion}

In this paper we report the results of the largest, randomised, controlled trial of a modified IUI technique, which was first described in $1992^{21}$

In standard IUI, a bolus of highly-concentrated spermatozoa is delivered directly into the uterine cavity near to the fallopian tubes to increase the density of capacitated spermatozoa near the presumed oocyte, thereby optimising the chance for pregnancy ${ }^{17}$. However, a proportion of the spermatozoa are expelled through the fallopian tubes into the peritoneal fluid ${ }^{26,27}$ when a volume of $0.5 \mathrm{ml}$ is used. This means that there is scope for improvement in this technique.

The concept underlying SRI is that a smaller number of spermatozoa continuously released into the uterus over an extended period of time will prolong the period of potential fertilisation, more closely mimicking physiological continuous sperm transportation into the fallopian tubes ${ }^{22}$. It could be hypothesised that this prolonged usage of the insemination balloon catheter in SRI also improves the transport of spermatozoa along the fallopian tubes by stimulating local prostaglandin production as a result of the pressure on the endocervix. However data about this hypothesis is very weak. Moreover, there is literature postulating a negative effect of inseminating too much sperm cells all at once ${ }^{5,28}$. These papers place this in the context of excessive reactive oxygen species (ROS) formation and multiple fertilization of the oocyte if too many sperm cells are present in the uterus or oviduct. Therefore slow release insemination with its duration of 4 hours and only inseminating few spermatozoa per minute could avoid this effect.

Muharib et al. were the first to report an improvement of pregnancy rates using this technique compared to the standard bolus technique ${ }^{21}$. A re-analysis of their data indicated that this difference failed to reach statistical significance $(p=0.057)^{22}$. A subsequent meta-analysis of data from the Muharib et al. study and two pilot studies demonstrated that SRI was statistically significantly more effective than IUI (RR 2.64; 95\% CI 1.04-6.74; $\mathrm{p}=0.02)^{22}$.

This randomised, controlled, multicentre trial demonstrated an overall numerically - but not statistically significant - higher pregnancy rate with the SRI procedure. In the subgroup of women aged under 35 years, pregnancy rates were significantly higher with the SRI procedure. Of note, women under 35 years of age are routinely referred for IUI, as falling pregnancy rates in older women might lead to earlier IVF treatment.

It is well known that pregnancy rates decrease with female age, whether or not artificial insemination is required $^{29-31}$. In their much larger study in patients undergoing IUI, Schorsch et al. reported statistically significantly higher pregnancy rates for women below the age of 25 compared to women aged 35 years and over $(\mathrm{p}<0.001)$, and they concluded that age was an important factor in achieving pregnancy after IUI ${ }^{31}$. The impact of male and female age on pregnancy rates after SRI needs to be analysed in further studies.

To exclude a bias on pregnancy rates by different stimulation methods within the treatment groups, we documented the method of stimulation (Tables 1 and 2). While generally there was no difference in the use of CC, rFSH or progesterone within the groups, an exceptionally high pregnancy rate in patients aged less than 35 years 


\begin{tabular}{|c|c|c|c|}
\hline & $\begin{array}{l}\text { IUI procedures } \\
(\mathbf{n}=\mathbf{8 3})\end{array}$ & $\begin{array}{l}\text { SRI procedures } \\
(\mathrm{n}=89)\end{array}$ & p-value \\
\hline Female age, years* & $31(28-33)$ & $30(28-33)$ & 0.864 \\
\hline Body Mass Index $\left(\mathrm{kg} / \mathrm{m}^{2}\right)^{*}$ & $21(20-24)$ & $22(20-24)$ & $>0.999$ \\
\hline \multicolumn{4}{|l|}{ Previous pregnancies } \\
\hline $0^{*}$ & $51(62 \%)$ & $62(70 \%)$ & 0.498 \\
\hline $1^{\#}$ & $26(31 \%)$ & $21(23 \%)$ & \\
\hline$>1^{\#}$ & $6(7 \%)$ & $6(7 \%)$ & \\
\hline \multicolumn{4}{|l|}{ Cause of infertility } \\
\hline Endometriosis $^{\#}$ & $4(5 \%)$ & $4(4 \%)$ & 0.490 \\
\hline Anovulation ${ }^{*}$ & $16(19 \%)$ & $24(27 \%)$ & \\
\hline Unexplained infertility $^{*}$ & $63(76 \%)$ & $61(69 \%)$ & \\
\hline Donor Insemination ${ }^{*}$ & $11(13 \%)$ & $9(10 \%)$ & 0.521 \\
\hline \multicolumn{4}{|l|}{ Reproductive Medication ${ }^{*}$} \\
\hline Clomiphene & 26 & 29 & 0.860 \\
\hline Gonadotropins & 54 & 59 & 0.865 \\
\hline Progesterone & 22 & 24 & 0.946 \\
\hline \multicolumn{4}{|l|}{ Concomitant Medication } \\
\hline Levothyroxine & 4 & 6 & 0.590 \\
\hline Other $^{\mathrm{c}}$ & 2 & 3 & $>0.999$ \\
\hline Male age, years* & $34(30-37)$ & $34(29-37)$ & 0.759 \\
\hline \multicolumn{4}{|l|}{ Semen analysis ${ }^{a}$} \\
\hline Concentration $(\mathrm{mio} / \mathrm{ml})^{*}$ & $45(22-78)$ & $40(15-76)$ & 0.398 \\
\hline Motility $(\%)^{*}$ & $54(43-76)$ & $52(43-69)$ & 0.291 \\
\hline Normal morphology $(\%)^{*}$ & $17(7-70)$ & $10(5-72)$ & 0.263 \\
\hline \multicolumn{4}{|l|}{ Treatment cycle } \\
\hline $1^{\#}$ & 55 & 57 & 0.760 \\
\hline $2^{\#}$ & 28 & 32 & \\
\hline
\end{tabular}

Table 2. Baseline characteristics of couples undergoing IUI and SRI procedures where the woman was aged under 35 years. IUI, intrauterine insemination; SRI, slow-release insemination. Data are presented as *median (interquartile range) or ${ }^{\#} \mathrm{n}(\%) .{ }^{*}$ Reproductive medication - data presented as cumulative reproductive

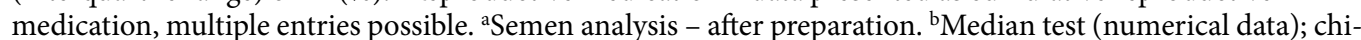
squared/Fishers' exact test (categorical data).

\begin{tabular}{|l|l|}
\hline Insemination method & Pregnancy rate (\%) \\
\hline All women & 11.6 \\
\hline SRI & 13.2 \\
\hline IUI & 10.0 \\
\hline Women $<35$ years & 12.2 \\
\hline SRI & $16.9 *$ \\
\hline IUI & 7.2 \\
\hline
\end{tabular}

Table 3. Pregnancy rates following slow release insemination and intrauterine insemination. IUI, intrauterine insemination; SRI, slow-release insemination. *Statistically significant.

\begin{tabular}{|l|l|l|}
\hline Event & $\begin{array}{l}\text { IUI procedure } \\
(\mathbf{n}=\mathbf{1 4 0})\end{array}$ & $\begin{array}{l}\text { SRI procedure } \\
(\mathbf{n}=\mathbf{1 4 4})\end{array}$ \\
\hline Post-interventional spotting & 1 & 3 \\
\hline Pain during catheter insertion & 0 & 2 \\
\hline $\begin{array}{l}\text { Pain and cramps during } \\
\text { procedure }\end{array}$ & 0 & 1 \\
\hline Vasovagal syncope & 0 & 1 \\
\hline Multiple pregnancies & 0 & 0 \\
\hline Ectopic pregnancies & 0 & 3 \\
\hline
\end{tabular}

Table 4. Adverse events. IUI, intrauterine insemination; SRI, slow-release insemination. 
using CC and undergoing SRI was found (24,1\%). Overall, however, no significant differences in the use of medications could be discovered in the treatment of women who became pregnant after SRI or IUI.

Values for absolute pregnancy rates with IUI differ widely in the literature; however, we could not find any other modification of the method or medication for IUI that had as strong an effect on pregnancy rates as SRI. This observation shows the potential benefit of SRI. IUI is a cost-effective method for increasing pregnancy rates in couples with unexplained infertility, which is why IUI is often chosen as first-line therapy in these patients ${ }^{32}$. One could speculate that an improvement in success rates with SRI might further reduce the number of referrals for more expensive assisted reproductive technology, and hence reduce the overall costs of infertility treatment; however, carefully designed clinical trials would be required to prove this.

We are aware that the cross-over design might be seen as a major limitation of this study. As already stated cross-over studies with repeated interventions on the same patient are not traditionally recommended for trials where a successful outcome will have a permanent serial effect (in this case, pregnancy) that results in the withdrawal of the patient from the second arm of the trial ${ }^{22}$. Pregnancy after the first treatment unbalances the research design and introduces a period effect. For this reason, some authors reject the utilisation of this study design in infertility trials ${ }^{33,34}$; however, others claim that it is an efficient and pragmatic design, particularly as only one cycle of each treatment is given to each woman ${ }^{23,24}$. To show this effect in our study, we evaluated the data from the first treatment course in patients aged under 35 years.

During the first cycle, 112 inseminations were performed in these patients; of these, 55 were randomised to the IUI procedure, and 57 to SRI. $5.5 \%$ and $14 \%$, respectively, resulted in pregnancy $(R R=2.57)$. This difference was not statistically significant (95\% CI for RR 0.72-9.20; $\mathrm{p}=0.073)$; however, this can be explained by a lack of statistical power due to the small number of treatments (actual power $=46 \%$ ). Cross-sectional studies have been shown to be a valid approach in infertility research: ${ }^{23}$ Takada et al. recently reported that the crossover design has the highest power and the smallest bias ${ }^{24}$. These authors recommended using a combination of a cross-over design and the Mantel-Haenszel method for two-period, two-treatment clinical trials with irreversible endpoints.

The mentioned considerations about sample size must also be included into the discussion about study limitations. The power calculation was done for the whole study population and not for women aged $<35$ years. Thus, the population size in the latter group is small and the analysis of this subgroup seems vulnerable to chance. This issue could have been solved by including women of younger age only which has not been the case.

The lack of information on previous infertility treatments and the use of donor sperm may additionally be seen as another limitation of the study. Moreover, two different types of sperm preparation methods may introduce bias. There were approximately equal numbers of IUI and SRI (19 IUI, 18 SRI) performed with donor sperm. This study, however, mainly included couples with unexplained infertility and not subfertile men, as sperm quality inclusion criteria were very strict. In this context we have to state that the sperm volume was not evaluated which we consider as minor study limitation.

The wide use of CC in the present study also must be discussed critically, as we are aware that this might be considered controversial. In accordance with the guidance from the Practice Group of the American Society for Reproductive Medicine, the relatively high rate of anovulation in both groups was addressed by administering $\mathrm{CC}^{35}$. The guidance notes that CC used in combination with IUI in cases of unexplained infertility seems to be beneficial. Up to three cycles is considered a common therapeutic regimen before progressing to more aggressive therapies. Last not least, despite the small sample size to achieve, the study period was quite long. Empirically, this was due to the fact that women did not accept IUI well and often opted for IVF instead. Moreover, the study was performed in 11 different centres around Europe which might have introduced some kind of unknown bias. However, since all centres performed IUI and SRI with similar frequency, we believe that this circumstance was of minor relevance. Interestingly, the only ectopic pregnancies reported in this study were following the SRI procedure. Althoug this difference was not statistically significant, the population size of this group is too small to draw any conclusions concerning safety regarding this point.

\section{Conclusion}

In conclusion, these data lend support to the hypothesis that the pregnancy rate might be improved by using SRI rather than IUI, especially in women aged less than 35 years. Due to the above-mentioned study limitations, this trial should be seen as an additional pilot study which can also serve as a basis for future trials. Thus, additional, larger, clinical trials are required to fully prove the hypothesis of SRI's superiority, especially if an economic benefit of SRI is also to be demonstrated, but also to evaluate potential adverse effects of this procedure with respect to the occurrence of ectopic pregnancies.

Received: 17 November 2019; Accepted: 7 April 2020;

Published online: 07 May 2020

\section{References}

1. Luke, B. Pregnancy and birth outcomes in couples with infertility with and without assisted reproductive technology: with an emphasis on US population-based studies. American journal of obstetrics and gynecology 217, 270-281, https://doi.org/10.1016/j. ajog.2017.03.012 (2017).

2. Cantineau, A. E., Janssen, M. J., Cohlen, B. J. \& Allersma, T. Synchronised approach for intrauterine insemination in subfertile couples. The Cochrane database of systematic reviews 12, CD006942, https://doi.org/10.1002/14651858.CD006942.pub3 (2014).

3. Soria, M. et al. Pregnancy predictors after intrauterine insemination: analysis of 3012 cycles in 1201 couples. Journal of reproduction \& infertility 13, 158-166 (2012).

4. Gomez, R. et al. The effect of ovarian stimulation on the outcome of intrauterine insemination. Archives of gynecology and obstetrics 289, 181-185 (2014).

5. Lemmens, L. et al. Techniques used for IUI: is it time for a change? Human reproduction 32, 1835-1845, https://doi.org/10.1093/ humrep/dex223 (2017). 
6. Gubert, P. G., Pudwell, J., Van Vugt, D., Reid, R. L. \& Velez, M. P. Number of motile spermatozoa inseminated and pregnancy outcomes in intrauterine insemination. Fertil Res Pract 5, 10, https://doi.org/10.1186/s40738-019-0062-z (2019).

7. Custers, I. M. et al. Intrauterine insemination: how many cycles should we perform? Human reproduction $23,885-888$, https://doi. org/10.1093/humrep/den008 (2008).

8. Haagen, E. C. et al. Subfertility guidelines in Europe: the quantity and quality of intrauterine insemination guidelines. Human reproduction 21, 2103-2109, https://doi.org/10.1093/humrep/del100 (2006).

9. Bakas, P. et al. Role of gonadotropin-releasing hormone antagonist in the management of subfertile couples with intrauterine insemination and controlled ovarian stimulation. Fertility and sterility 95, 2024-2028, https://doi.org/10.1016/j. fertnstert.2011.01.167 (2011)

10. Berker, B. et al. Recombinant FSH versus clomiphene citrate for ovarian stimulation in couples with unexplained infertility and male subfertility undergoing intrauterine insemination: a randomized trial. Archives of gynecology and obstetrics 284, 1561-1566, https:// doi.org/10.1007/s00404-011-1997-4 (2011).

11. Cantineau, A. E., Cohlen, B. J., Klip, H., Heineman, M. J. \& Dutch, I. U. I. S. G. C. The addition of GnRH antagonists in intrauterine insemination cycles with mild ovarian hyperstimulation does not increase live birth rates-a randomized, double-blinded, placebocontrolled trial. Human reproduction 26, 1104-1111, https://doi.org/10.1093/humrep/der033 (2011).

12. Kar, S. Current evidence supporting "letrozole" for ovulation induction. Journal of human reproductive sciences 6, 93-98, https://doi. org/10.4103/0974-1208.117166 (2013).

13. Lewis, V., Queenan, J. Jr., Hoeger, K., Stevens, J. \& Guzick, D. S. Clomiphene citrate monitoring for intrauterine insemination timing: a randomized trial. Fertility and sterility 85, 401-406, https://doi.org/10.1016/j.fertnstert.2005.07.1331 (2006).

14. Custers, I. M. et al. Immobilisation versus immediate mobilisation after intrauterine insemination: randomised controlled trial. $B M J$ 339, b4080, https://doi.org/10.1136/bmj.b4080 (2009).

15. Cordary, D. et al. Immobilization versus immediate mobilization after intrauterine insemination: A systematic review and metaanalysis. J Gynecol Obstet Hum Reprod 46, 747-751, https://doi.org/10.1016/j.jogoh.2017.09.005 (2017).

16. Saleh, A., Tan, S. L., Biljan, M. M. \& Tulandi, T. A randomized study of the effect of 10 minutes of bed rest after intrauterine insemination. Fertility and sterility 74, 509-511, https://doi.org/10.1016/s0015-0282(00)00702-0 (2000).

17. Peivandi, S., Ebadi, A. \& Modanlu, S. The comparison between Intrauterine Insemination and Fallopian Tube Sperm Perfusion Using FAST(R)System in Patients with Unexplained Infertility. International journal of fertility \& sterility 8, 379-384 (2015).

18. Cantineau, A. E., Cohlen, B. J., Heineman, M. J., Marjoribanks, J. \& Farquhar, C. Intrauterine insemination versus fallopian tube sperm perfusion for non-tubal infertility. The Cochrane database of systematic reviews 10, CD001502, https://doi. org/10.1002/14651858.CD001502.pub4 (2013).

19. Hurd, W. W. et al. Comparison of intracervical, intrauterine, and intratubal techniques for donor insemination. Fertility and sterility 59, 339-342 (1993)

20. Ransom, M. X., Blotner, M. B., Bohrer, M., Corsan, G. \& Kemmann, E. Does increasing frequency of intrauterine insemination improve pregnancy rates significantly during superovulation cycles? Fertility and sterility 61, 303-307 (1994).

21. Muharib, N. S., Abdel Gadir, A. \& Shaw, R. W. Slow release intrauterine insemination versus the bolus technique in the treatment of women with cervical mucus hostility. Human reproduction 7, 227-229 (1992).

22. Marschalek, J. et al. The effect of slow release insemination on pregnancy rates: report of two randomized controlled pilot studies and meta-analysis. Archives of gynecology and obstetrics 295, 1025-1032, https://doi.org/10.1007/s00404-017-4290-3 (2017).

23. McDonnell, J., Goverde, A. J. \& Vermeiden, J. P. The place of the crossover design in infertility trials: a maximum likelihood approach. Human reproduction 19, 2537-2544, https://doi.org/10.1093/humrep/deh475 (2004).

24. Takada, M., Sozu, T. \& Sato, T. Practical approaches for design and analysis of clinical trials of infertility treatments: crossover designs and the Mantel-Haenszel method are recommended. Pharmaceutical statistics 14, 198-204, https://doi.org/10.1002/pst.1674 (2015).

25. Merviel, P. et al. Predictive factors for pregnancy after intrauterine insemination (IUI): an analysis of 1038 cycles and a review of the literature. Fertility and sterility 93, 79-88, https://doi.org/10.1016/j.fertnstert.2008.09.058 (2010).

26. Englert, Y., Puissant, F., Camus, M., Degueldre, M. \& Leroy, F. Factors leading to tripronucleate eggs during human in-vitro fertilization. Human reproduction 1, 117-119 (1986).

27. Ripps, B. A., Minhas, B. S., Carson, S. A. \& Buster, J. E. Intrauterine insemination in fertile women delivers larger number of sperm to the peritoneal fluid than intracervical insemination. Fertility and sterility 61, 398-400 (1994).

28. Thijssen, A. et al. Predictive value of different covariates influencing pregnancy rate following intrauterine insemination with homologous semen: a prospective cohort study. Reproductive biomedicine online 34, 463-472, https://doi.org/10.1016/j. rbmo.2017.01.016 (2017).

29. Belloc, S. et al. Effect of maternal and paternal age on pregnancy and miscarriage rates after intrauterine insemination. Reproductive biomedicine online 17, 392-397 (2008).

30. Jatzko, B. et al. The impact of thyroid function on intrauterine insemination outcome-a retrospective analysis. Reproductive biology and endocrinology: RB\&E 12, 28, https://doi.org/10.1186/1477-7827-12-28 (2014).

31. Schorsch, M. et al. Success Rate of Inseminations Dependent on Maternal Age? An Analysis of 4246 Insemination Cycles. Geburtshilfe und Frauenheilkunde 73, 808-811, https://doi.org/10.1055/s-0033-1350615 (2013).

32. Bahadur, G., Homburg, R. \& Al-Habib, A. A New Dawn for Intrauterine Insemination: Efficient and Prudent Practice will Benefit Patients, the Fertility Industry and the Healthcare Bodies. Journal of obstetrics and gynaecology of India 67, 79-85, https://doi. org/10.1007/s13224-016-0928-5 (2017).

33. Barlow, D. H. The design, publication and interpretation of research in Subfertility Medicine: uncomfortable issues and challenges to be faced. Human reproduction 18, 899-901 (2003).

34. Daya, S. Pitfalls in the design and analysis of efficacy trials in subfertility. Human reproduction 18, 1005-1009 (2003).

35. Practice Committee of the American Society for Reproductive. M. Use of clomiphene citrate in infertile women: a committee opinion. Fertility and sterility 100, 341-348, https://doi.org/10.1016/j.fertnstert.2013.05.033 (2013).

\section{Acknowledgements}

The authors thank Jane Tricker, freelance medical writer and editor, (Elmcroft Editorial Services Ltd, Maidstone, Kent, UK) for assistance with preparing the manuscript for publication. The authors also thank the following investigators and study centres for their participation in the study: Prof. Dr. med. J. Neulen, Universitätsklinikum Aachen, Germany. Dr. med. N. Sänger und Dr. med. S. Becker, Klinikum der Johann Wolfgang-von-Goethe Universität, Frankfurt a. Main, Germany. Prof Dr. med. A. Obruca, Kinderwunschzentrum der Goldenes Kreuz Privatklinik, Wien, Austria. Dr. med. I. Alba-Alejandre/Prof. Dr. med. C. J Thaler, LMU, Klinikum der Universität München, Germany. Dr. med. J. Krüsmann, Kinderwunsch Zentrum, München Pasing, Germany. Mr Wael Saab, Centre for Reproductive and Genetic Health, The Centre for Reproductive \& Genetic Health, London, UK. Dr. M. Schenk, Kinderwunsch Institut Schenk GmbH, Dobl, Austria. Funding for the study was provided by the sponsor, Reproductive Sciences Ltd. The sponsor had no involvement in the data analysis or decision to write or submit the 
article for publication, but provided funding for independent statistical analysis and editorial assistance. Financial responsibility on side of the authors: Maximilian Franz,.M.D. (corresponding author).

\section{Author contributions}

Julian Marschalek, Data management, Manuscript writing/editing. Christian Egarter, Study design, Data collection, Manuscript editing. Elisabeth Vytiska-Binsdorfer, Study design, Data collection, Manuscript editing. Andreas Obruca, Study design, Data collection, Manuscript editing. Jackie Campbell, Data management/ analysis, Manuscript writing/editing. Philip Harris, Study design, Data collection, Manuscript editing. Maarten van Santen, Study design, Data collection, Manuscript editing. Bernd Lesoine, Study design, Data collection, Manuscript editing. Johannes Ott, Data management, Manuscript writing/editing. Maximilian Franz, Study desing, Data collection, Data management, Manuscript writing/editing.

\section{Competing interests}

J.M., C.E., E.V.-B., J.O., M.F., Mv.S. and P.H. received payments on behalf of their institutions for each treatment performed under the study agreement and further benefited from the statistical analysis and editorial support provided by the sponsor but report no other conflicts of interest. J.C. received payment from the sponsor as an independent statistical consultant but reports no other conflict of interest.

\section{Additional information}

Correspondence and requests for materials should be addressed to M.F.

Reprints and permissions information is available at www.nature.com/reprints.

Publisher's note Springer Nature remains neutral with regard to jurisdictional claims in published maps and institutional affiliations.

(c) (i) Open Access This article is licensed under a Creative Commons Attribution 4.0 International License, which permits use, sharing, adaptation, distribution and reproduction in any medium or format, as long as you give appropriate credit to the original author(s) and the source, provide a link to the Creative Commons license, and indicate if changes were made. The images or other third party material in this article are included in the article's Creative Commons license, unless indicated otherwise in a credit line to the material. If material is not included in the article's Creative Commons license and your intended use is not permitted by statutory regulation or exceeds the permitted use, you will need to obtain permission directly from the copyright holder. To view a copy of this license, visit http://creativecommons.org/licenses/by/4.0/.

(C) The Author(s) 2020 